\title{
THROMBI IN THE HEPATIC SINUSOIDS OF THE NEWBORN AND THEIR RELATION TO PULMONARY HYALINE MEMBRANE FORMATION
}

\author{
BY \\ T. WADE-EVANS \\ From the Departments of Pathology and Obstetrics, University of Manchester
}

(RECEIVED FOR PUBLICATION AUGUST 15, 1960)

An increase in the degree of fatty change of the liver was found by Benitez (1952) in babies who had aspirated vernix caseosa or who had pulmonary hyaline membranes, but little else has been recorded about hepatic lesions in such cases. The observation of small thrombi in the sinusoids of the livers of babies with hyaline membranes was thus of interest; the investigation reported in this paper was undertaken to determine the general incidence of such sinusoidal thrombi in stillbirths and in babies dying in the neonatal period, and to examine their relation to pulmonary hyaline membrane formation. In addition, a survey was made of livers taken at autopsy from adult patients, in a smaller proportion of whom similar thrombi are found; Popper and Schaffner (1957) review reports of the occurrence of sinusoidal thrombi in eclampsia, although, as will be shown, these may occur where there is similar circulatory disturbance or focal necrosis of any cause.

\section{Observations and Methods}

The thrombi within the sinusoids of the liver are difficult to detect in sections stained by haematoxylin and eosin, but they stain prominently as fibrin with phosphotungstic-acid haematoxylin or the picro-Mallory method. The latter gives the better colour contrast batween thrombi and erythrocytes or parenchymal cells and was used on all the material we examined. The method of McFarlane (1944) was slightly modified to suit the formalin fixed tissue available.

The thrombi are small, being sometimes formed of separate strands of fibrin but more often compact and rounded, as if moulded by the blood stream (Fig. 1). They are usually single, but may form groups of two or three, and less often lip to five or six. They are not confined to any one zone of the liver lobule. They are discrete, and are not continuous with thrombus in the larger vessels of the liver; although observations on the main portal, hepatic or umbilical veins, and on the hepatic artery were not recorded, examination of the sections shows thrombus to be uncommon in the branches of these vessels. There is much variation in the liver tissue adjacent to the thrombi; some of the parenchymal cells are normal, while others show vacuolation or shrinkage in different degrees, and the amount of haemopoietic tissue varies. Histological assessment of these changes was not attempted. In four cases in which thrombi were numerous small areas of necrosis were seen, and within these thrombosis was extensive but more diffuse.

When a larger series of livers was examined it was

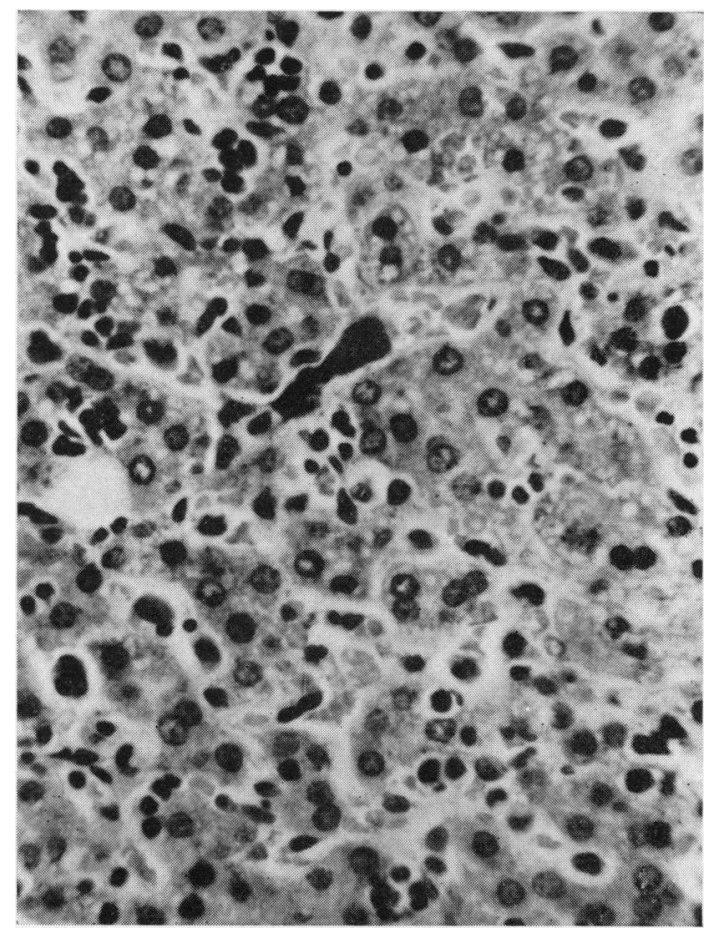

FIG. 1.-A rounded and compact thrombus in a hepatic sinusoid. The baby weighed $1.39 \mathrm{~kg}$. at birth and died at 27 hours with extensive hyaline membrane formation. (Picro-Mallory $\times 340$.) 
TABLE 1

THROMBI IN HEPATIC SINUSOIDS: UNSELECTED CASES, 1956-57

\begin{tabular}{|c|c|c|c|c|c|c|c|c|c|c|}
\hline & & \multicolumn{9}{|c|}{ Counts per 50 Fields } \\
\hline & & 0 & $1-4$ & $5-9$ & $10-14$ & $15-19$ & $20-24$ & $25-29$ & $30+$ & Total \\
\hline $\begin{array}{l}\text { All neonatal deaths } \\
\text { With hyaline membranes } \\
\text { Others .. } \\
\text { Stillbirths }\end{array}$ & $\begin{array}{l}. . \\
\therefore \\
\cdots\end{array}$ & $\begin{array}{r}68 \\
3 \\
65 \\
110\end{array}$ & $\begin{array}{l}38 \\
10 \\
28 \\
12\end{array}$ & $\begin{array}{l}3 \\
1 \\
2 \\
0\end{array}$ & $\begin{array}{l}6 \\
5 \\
1 \\
1\end{array}$ & $\begin{array}{r}10 \\
8 \\
2 \\
0\end{array}$ & $\begin{array}{l}2 \\
1 \\
1 \\
1\end{array}$ & $\begin{array}{l}4 \\
4 \\
0 \\
2\end{array}$ & $\begin{array}{l}5 \\
2 \\
3 \\
5\end{array}$ & $\begin{array}{r}136 \\
34 \\
102 \\
131\end{array}$ \\
\hline
\end{tabular}

found that thrombi were in fact present in many, although their number varied greatly. In order to separate those cases in which they were absent or few, from those in which they were more numerous, counts were made. Using $\times 20$ objective, thrombi were counted in groups of 50 fields, taking these in line backwards and forwards across the section, and starting where possible at right angles to the serous surface. The thrombi were not counted within areas of necrosis, nor were fields of which necrosis, vessels or portal tracts formed more than half. Between two and eight groups of fields were counted, according to the area of the section, and the means of the counts calculated. The magnification used was the lowest that allowed thrombi to be distinguished from other structures which stained red with the picroMallory method.

The investigation was conducted in several steps.

The incidence of thrombi in an unselected group of babies dying in the neonatal period was determined, taking all those examined at autopsy in the years 1956 and 1957 from whom blocks of liver tissue were available. Blocks were of two sorts; the first had been taken at random, wnile the second, of distinctive shape, had been taken specifically from the right and left lobes. At this stage the random blocks were used, or, if these were not available, those fiom the right and left lobes were taken together; possible differences between the lobes were considered separately. Livers from stillbirths were also examined; this series was selected in that liver tissue had bein processed only from the unmacerated, so that it was confined to babies dying at or shortly before birth. As this part of the survey appeared to establish further the association with hyaline membranes, but did not provide a sufficiently large number of livers to form a suitable control series, additional cases from the preceding three years 1953-55 both with and without hyaline membranes, were selected for examination. Finally, to determine whether similar thrombi occuured more widely in the body, sections of spleen, kidney and adrenal, were examined from those cases in which, in the liver, they were numerous.

\section{Results}

Thrombi in Unselected Neonatal Deaths. Sections were examined from 139 livers, but three were excluded because they contained pyaemic abscesses with much surrounding diffuse thrombosis. The counts from the remaining 136 are presented in Table 1.
In $68(50 \%)$ no thrombi were found and in 38 $(28 \%)$ they were few in number, usually one or two and never more than five per 50 fields; in 27 there were 10 or more per 50 fields. In the further analysis of these results cases with counts of 10 or more are compared with those having less; the former are referred to as 'positive' and the latter as 'negative' cases.

The number of thrombi in babies with and without primary hyaline membranes is compared in the histogram (Fig. 2). This comparison suggests that there is indeed an association between hyaline membrane formation and an increase in the number of thrombi, and of the 27 positive cases no fewer than 20 also had membranes. The two groups, however, those with and those without hyaline membranes, cannot be directly compared; most of the babies with hyaline membranes were premature and had died within a short time of birth, while in the remaining cases there was a much wider range of birth weight and survival. In general, because of such differences, comparison of a group of babies having hyaline membranes with the remaining cases from the same autopsy series will cause confusion by drawing attention not only to those factors related to hyaline membrane formation, but to those related independently to prematurity or to early death. This can be avoided by using a control series matched with the hyaline membrane series by age and maturity. In the group examined in this part of the investigation few cases could be matched in this way, and it was necessary to examine additional ones to form the control series defined in the next section.

Before these results are presented it is of interest to note certain groups in which an increase in the number of thrombi might be expected, but which were in fact 'negative'. First, there were 10 cases in which subcapsular haemorrhage was noted in the liver at autopsy, two of these having in addition small lacerations and a third small areas of necrosis. Second, exchange transfusion through the umbilical vein had been performed on 14 of the 17 babies with haemolytic disease; in one baby who had no fewer than five exchanges, no thrombi were found. 


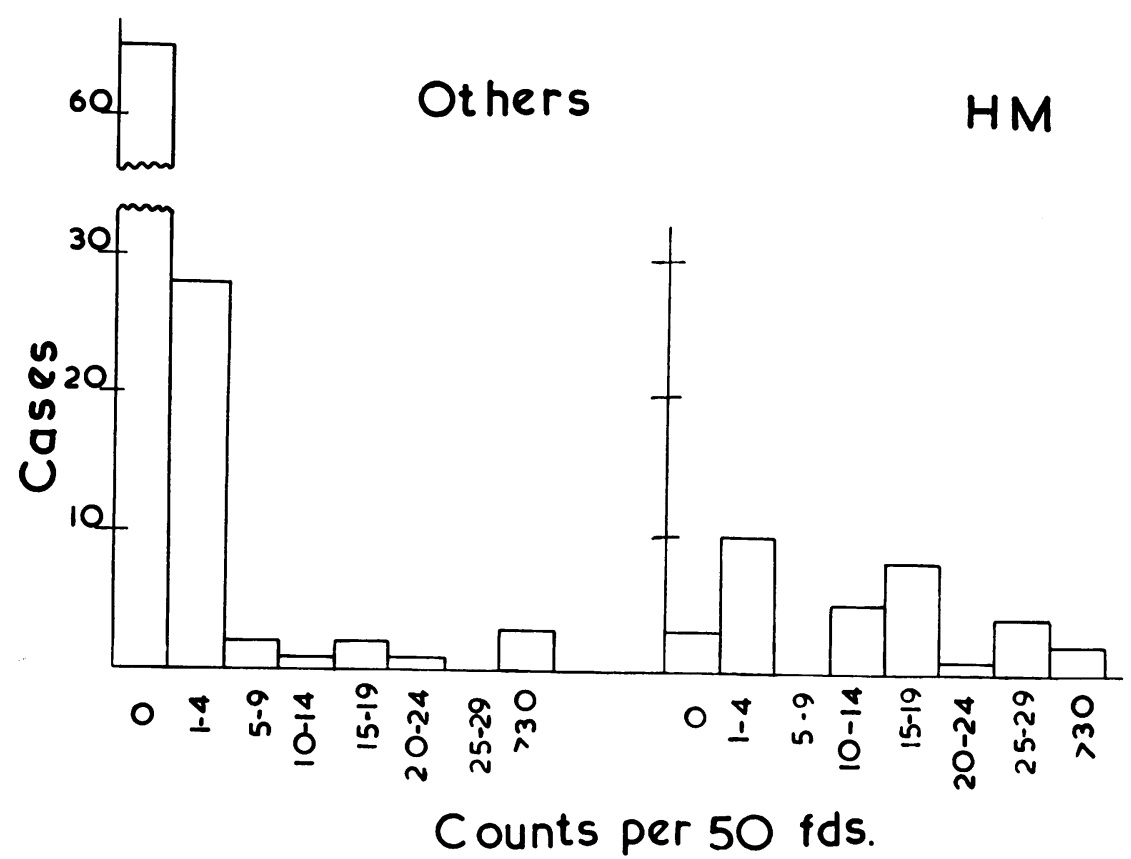

FIG. 2.-Counts of liver thrombi in cases with hyaline membranes (right) and others (left) from the unselected series examined.

Of the 131 fresh stillbirths examined (Table 1) $110(84 \%)$ showed no thrombi, and only nine cases $(6.9 \%)$ were 'positive'.

Hyaline Membranes and Matched Control Series, 1953-57. The range of the investigation was extended by including further livers from babies dying with hyaline membranes in the years 1953-55; in the whole five-year period blocks of liver were examined from 70 such cases. Most babies with hyaline membranes are premature by the accepted convention of birth weight, and relatively few die who survive for 48 hours; of the 70 cases, 62 were both premature by birth weight and had lived more than one but less than 48 hours after birth. A control series of the same range of birth weight and age was selected from the cases already examined, with additional cases from the years 1953-55; babies with gross congenital malformations were excluded, but otherwise all from whom blocks were available were examined. There were 60 such controls.

The counts from all the cases with hyaline membranes, and from the matched series, are presented in Table 2 and Fig. 3. The increased incidence of 'positive' cases among the babies with hyaline membranes is statistically highly significant (Table 3 ).

There were, however, 11 'positive' controls and a search was made for factors common to them and the positive cases with hyaline membranes. Two types of lesion appeared on first examination to merit further investigation (Table 4). First, the incidence of intracranial lesions among the positive controls was high, for three had intraventricular haemorrhage, one tentorial tearing with subdural haemorrhage, and one haemorrhage into the falx; in addition, of the four positive cases from the unselected 1956-57 group not included among these premature controls, two had kernikterus, one a tentorial tear, and one was an iniencephalic. Second,

TABLE 2

THROMBI IN HEPATIC SINUSOIDS: MATCHED CONTROL AND HYALINE MEMBRANE SERIES

\begin{tabular}{|c|c|c|c|c|c|c|c|c|c|}
\hline & \multicolumn{9}{|c|}{ Counts per 50 Fields } \\
\hline & 0 & $1-4$ & $5-9$ & $10-14$ & $15-19$ & $20-24$ & $25-30$ & $30+$ & Total \\
\hline $\begin{array}{l}\text { Premature controls } \\
\text { Matched hyaline membranes } \quad . . \\
\text { All cases with hyaline membranes }\end{array}$ & $\begin{array}{l}31 \\
14 \\
15\end{array}$ & $\begin{array}{l}17 \\
15 \\
17\end{array}$ & $\begin{array}{l}1 \\
2 \\
2\end{array}$ & $\begin{array}{r}3 \\
10 \\
13\end{array}$ & $\begin{array}{r}1 \\
9 \\
10\end{array}$ & $\begin{array}{l}\mathbf{2} \\
\mathbf{3} \\
\mathbf{3}\end{array}$ & $\begin{array}{l}1 \\
4 \\
5\end{array}$ & $\begin{array}{l}4 \\
5 \\
5\end{array}$ & $\begin{array}{l}60 \\
62 \\
70\end{array}$ \\
\hline
\end{tabular}




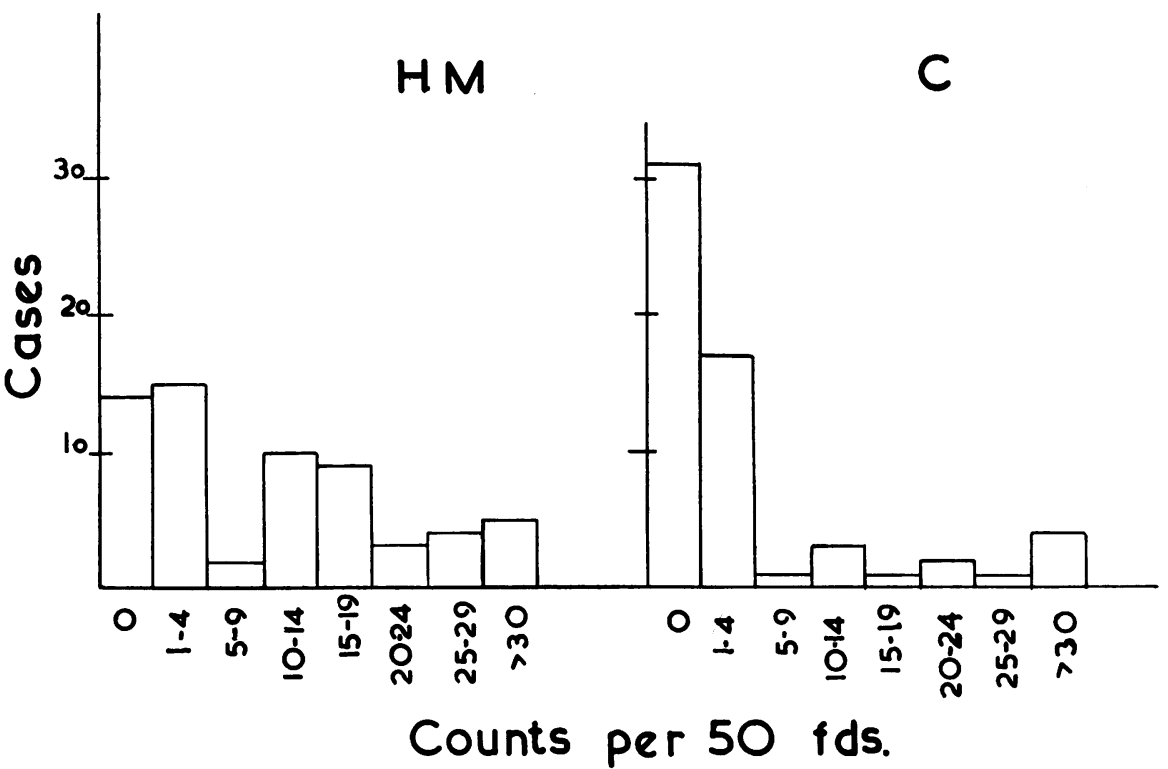

Fig. 3.-Counts of liver thrombi in premature babies living less than $\mathbf{4 8}$ hours with hyaline membranes (left) and in matched controls (right).

pneumonia was found in five cases, including two with intracranial lesions, one with renal agenesis, and two who had no other major lesion. The remaining three cases showed only the pleural or pericardial haemorrhages of anoxia, with pulmonary immaturity or atelectasis. However, the distribution of intracranial lesions and of pneumonia among positive and negative cases in both the control series and the hyaline membrane series did not
TABLE 3

MATCHED SERIES

\begin{tabular}{c|c|c|c}
\hline & Positive & Negative & Total \\
\hline $\begin{array}{c}\text { Premature controls . } \\
\text { Matched hyaline membranes .. }\end{array}$ & $\begin{array}{c}11 \\
31\end{array}$ & $\begin{array}{l}49 \\
31\end{array}$ & $\begin{array}{c}60 \\
62\end{array}$ \\
\hline & 42 & 80 & 122 \\
\hline $\begin{array}{c}\chi^{2}=13.88 \\
\mathrm{p}<0.001\end{array}$
\end{tabular}

TABLE 4

THROMBI IN HEPATIC SINUSOIDS: POSITIVE CONTROL CASES

\begin{tabular}{|c|c|c|c|c|c|c|}
\hline $\begin{array}{l}\text { Case } \\
\text { No. }\end{array}$ & Sex & $\begin{array}{c}\text { Birth Weight } \\
(\mathbf{k g} .)\end{array}$ & $\begin{array}{l}\text { Crown-Heel } \\
\text { Length } \\
\text { (cm.) }\end{array}$ & $\begin{array}{l}\text { Gestation } \\
\text { (wks) }\end{array}$ & $\begin{array}{c}\text { Age } \\
\text { (hrs) }\end{array}$ & Remarks \\
\hline $\begin{array}{c}\text { Premat } \\
1 \\
2 \\
3 \\
4 \\
5 \\
6 \\
7 \\
8 \\
9 \\
10 \\
11\end{array}$ & \begin{tabular}{c|} 
Controls \\
$\mathbf{F}$ \\
$\mathbf{M}$ \\
$\mathbf{F}$ \\
$\mathbf{M}$ \\
$\mathbf{M}$ \\
$\mathbf{M}$ \\
$\mathbf{F}$ \\
$\mathbf{M}$ \\
$\mathbf{M}$ \\
$\mathbf{F}$ \\
$\mathbf{F}$
\end{tabular} & $\begin{array}{l}2.09 \\
0.94 \\
0.86 \\
0.76 \\
1 \cdot 3 \\
1.32 \\
1 \cdot 13 \\
1.52 \\
1.02 \\
0.73 \\
0.66\end{array}$ & $\begin{array}{l}49 \\
34 \\
36 \\
36 \\
39 \\
40 \\
39 \\
41 \\
37 \\
33 \\
31\end{array}$ & $\begin{array}{l}41 \\
27 \\
32 \\
29 \\
30 \\
41 \\
35 \\
28 \\
30 \\
26\end{array}$ & $\begin{array}{r}24 \\
5 \\
24 \\
28 \\
6 \\
36 \\
24 \\
5 \\
8 \frac{1}{2} \\
12 \\
5\end{array}$ & $\begin{array}{l}\text { Petechiae of pericardium } \\
\text { Intraventricular haemorrhage; pneumonia } \\
\text { Petechiae of pericardium } \\
\text { Petechiae of pericardium } \\
\text { Intraventricular haemorrhage; pneumonia } \\
\text { Tentorial tear and haemorrhage } \\
\text { Petechiae of pleura and pericardium } \\
\text { Renal agenesis; pneumonia } \\
\text { Haemorrhage into falx; pneumonia } \\
\text { Pneumonia } \\
\text { Intraventricular haemorrhage }\end{array}$ \\
\hline $\begin{array}{c}\text { Others } \\
12 \\
13 \\
14 \\
15\end{array}$ & $\begin{array}{l}\mathbf{F} \\
\mathbf{M} \\
\mathbf{M} \\
\mathbf{M}\end{array}$ & $\begin{array}{l}1 \cdot 78 \\
2 \cdot 6 \\
3 \cdot 26 \\
2 \cdot 74\end{array}$ & $\begin{array}{l}\overline{46} \\
53 \\
50\end{array}$ & $\begin{array}{l}37 \\
35 \\
43 \\
36\end{array}$ & $\begin{array}{l}5 \text { days } \\
3 \text { days } \\
17 \\
53\end{array}$ & $\begin{array}{l}\text { Iniencephaly } \\
\text { Kernikterus (familial acholuric jaundice) } \\
\text { Tentorial tear and haemorrhage } \\
\text { Kernikterus; haemolytic disease }\end{array}$ \\
\hline
\end{tabular}




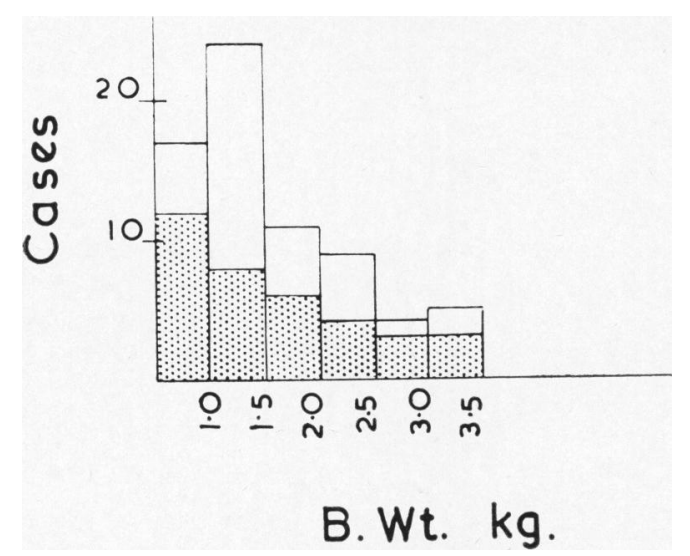

FIG. 4.-The distribution by birth weight of 70 babies with pulmonary hyaline membranes, in $0.5 \mathrm{~kg}$. groups. The 'positive' cases are shaded.

suggest that either of these lesions was significantly associated with the formation of thrombi.

An unsuccessful attempt was made to find differences between the 'positive' and 'negative' hyaline membrane cases. Significant differences were not found on examination of their distribution by birth weight (Fig. 4) or by age (Fig. 5), nor when the hyaline membranes were graded histologically for their extent or stage of formation. The incidence of other factors, including the method of delivery, the maternal age or parity, and a history of complications such as pre-eclampsia, antepartum haemorrhage or multiple pregnancy, did not differ between the two groups.

Distribution of Thrombi in Right and Left Lobes of Liver. In recent years attention has been drawn to changes in the liver which reflect either the peculiar pattern of its circulation in the foetus or the alterations in circulation after birth. The vascular supply of the two lobes differs in the foetus. Oxygenated blood returns from the placenta by way of the umbilical vein and, while in part it passes directly to the inferior vena cava by way of the ductus venosus, much of it circulates through the liver; the arrangement of veins is such that the left lobe receives a greater share of this enriched blood. At birth the umbilical vein is obliterated and the ductus closes, probably at once; the difference between the two lobes is then no greater than in the adult. Two consequences of these phenomena have been reported: first, in stillbirths and in some neonatal deaths degenerative changes caused by intrauterine anoxia are more marked in the right lobe (Gruenwald, 1949), and, second, after birth there is a rapid involution of the left lobe with loss of weight,

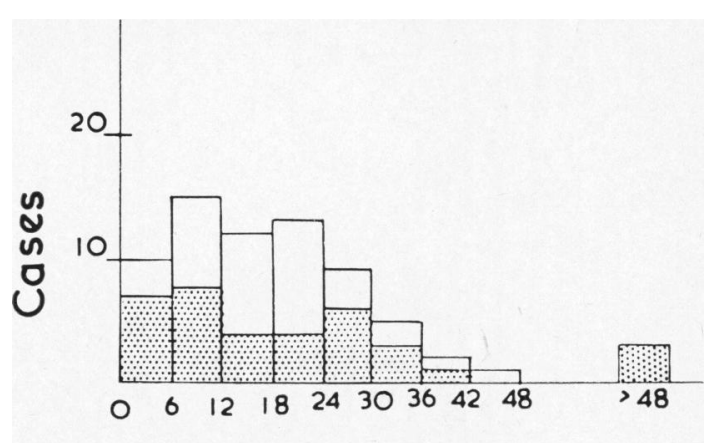

\section{Age in hours}

FIG. 5.-The distribution by age of 70 babies with pulmonary hyaline membranes, in six-hour groups. The 'positive' cases are shaded.

cellular shrinkage and, at certain periods, a greater content of fat (Emery, 1952; 1953; 1956; Emery and Finch, 1954).

As this change of circulation might be thought to cause the formation of thrombi, or to influence their distribution, the cases in which separate blocks had been taken from the right and left lobes of the liver were examined further. Altogether, there were 30 pairs of blocks from the 'positive' cases, 24 of which had hyaline membranes, and 22 from the 'negative' cases. In none of the negative cases did study of the two further sections show a larger number of thrombi on either side. Mean counts for the two sides in the positive cases are presented in Fig. 6; in only two is there a marked preponderance in the left lobe. Comparison of the difference of the means in individual cases did not show a significant increase on either side. While the number of cases examined was small the results did not suggest that this component of the circulatory change at birth had an important influence on the formation of thrombi.

Other Observations. The possibility that the presence of thrombi is not confined to the liver but is more general, was also considered. To examine this, blocks of the spleens, adrenals, kidneys and lungs, from the first 40 positive cases, were recut and stained by the picro-Mallory method. A widespread incidence of capillary or sinusoidal thrombi was not found. In the $\mathbf{4 0}$ kidneys examined, no thrombi were seen in the cortices, and single thrombi in the outer medullae of four; a single small thrombus was found in the pulp of one of the 38 spleens; one of the 34 adrenals had a few thrombi within an area of necrosis in the cortex; capillary thrombi 


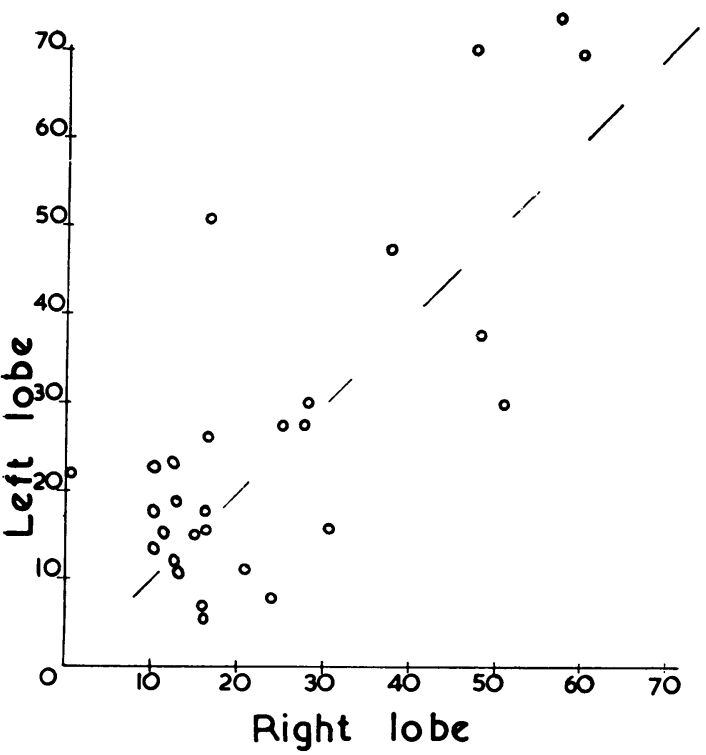

Fig. 6.-Comparison of counts of liver thrombi from the right and left lobes of 'positive' cases.

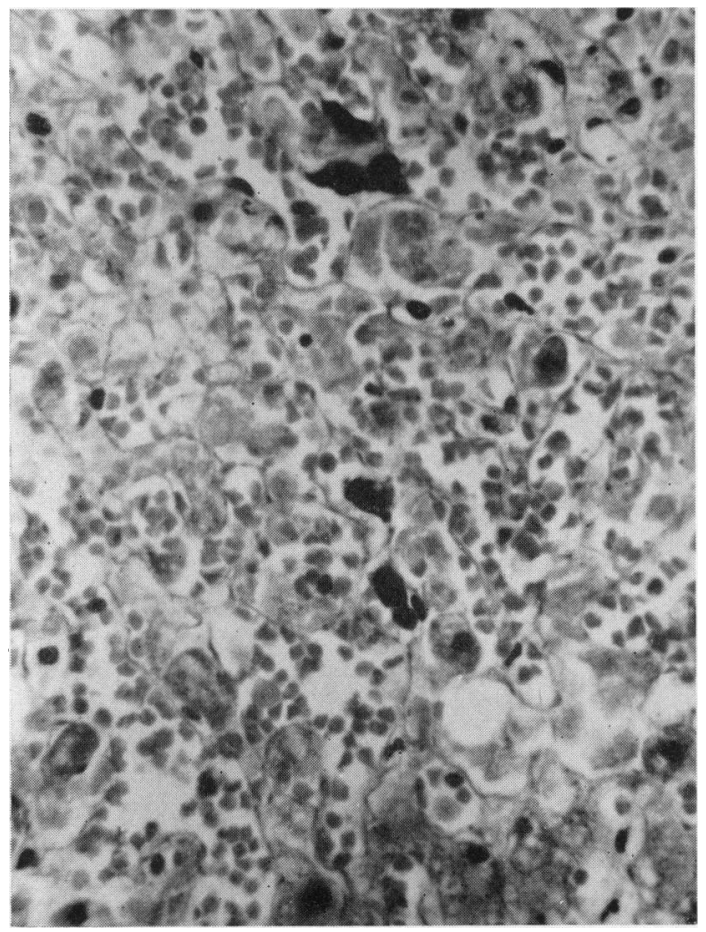

FIG. 7.-Sinusoidal thrombi in the liver of an adult with chronic venous congestion due to cor pulmonale. (Picro-Mallory $\times 420$.) were found in three of the 40 lungs, with larger thrombi in small arteries of four others. It was concluded that among the organs examined thrombi were numerous only in the liver.

To find out if thrombi were formed in the hepatic sinusoids of older patients, sections from 246 adult autopsies were examined after staining by the picro-Mallory method. The cases were not selected, being roughly consecutive. The histological changes found are summarized in Table 5. Thrombi similar in form to those seen in the newborn were found in only 20 cases, including 14 of the 24 with chronic venous congestion (Fig. 7), five of the 11 with focal necrosis, and one of the 18 with severe fatty change. In most of the livers thrombi were few in number; they were numerous only in four cases with chronic venous congestion, and in these some recent necrosis in the central parts of the lobule was also seen. In the cases with chronic congestion the thrombi usually lay in the central atrophic zone, but were sometimes seen outside this between apparently normal parenchymal cells; where there was focal necrosis the thrombi were found between the necrotic cells, and, as in the newborn, the thrombosis was occasionally more diffuse.

TABLE 5

THROMBI IN HEPATIC SINUSOIDS OF ADULTS

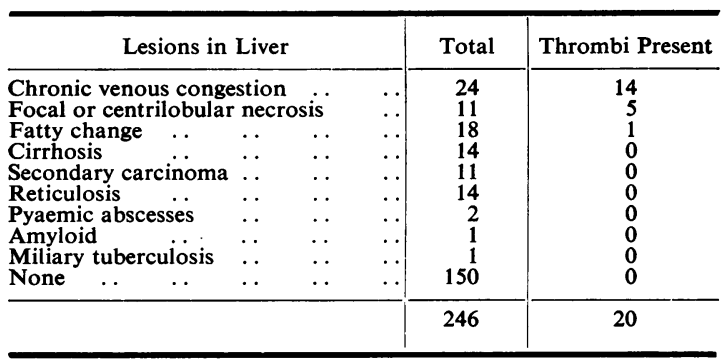

These observations are of interest, for they give an indication of the circumstances under which sinusoidal thrombi may form. In all cases but one there had been circulatory disturbance, either prolonged, as in chronic venous congestion, or more acute, as in the cases with focal necrosis in which cell death was caused by anoxia at sites determined by local reduction in blood flow. The occurrence of thrombi in larger numbers in cases of heart failure only where there is recent necrosis suggests that their formation is probably less the result of the chronic congestion than of a later exacerbation of failure with further decrease in cardiac output. 


\section{Discussion}

Several explanations of the genesis of the lesions found in the livers of the newborn are possible, but certain of these may be readily discounted. First, these are true thrombi and have not formed after death; although a cellular reaction to them has not been seen, their rounded and compact form suggests exposure to the blood flow during life and contrasts with the regular pattern of fibrin strands seen in post-mortem clot; their distribution in the body is not general. Second, the possibility of their being embolic must be considered. There are three routes by which emboli could reach the liver, the umbilical and portal veins, and the hepatic artery. Those carried by the hepatic artery should, however, be more widely distributed, at least to those organs supplied by the descending aorta. There is nothing to suggest the constant presence of any lesion in the field of drainage of the portal vein in these cases. Emboli could be carried through the umbilical vein only before birth, when they would be expected to be found more frequently in stillborn infants, to be found in larger numbers in the left lobe of the liver and also to pass into the general circulation by way of the ductus venosus and the foramen ovale. The distribution of thrombus formed by the action of any agent carried in the blood should be similar; it has been suggested (Boyd, 1958) that certain of the small thrombi seen in the lungs of newborn babies are, like those seen in women dying after amniotic fluid embolism, formed by the action of thrombogenic substances from the placenta.

The hypothesis most in accord with the observations made is that the thrombi form in the site in which they are seen, in the baby as in the adult, as a result of a disturbance of circulation leading to its local reduction with consequent anoxia, a process which when severe may cause in addition focal necrosis. This is of interest, for it now seems likely that pulmonary hyaline membranes arise by the compaction of fibrin-containing oedema fluid, and that a disorder of circulation contributes, in the newborn as in certain older patients, to membrane formation. The importance of the occurrence of large numbers of thrombi in babies with hyaline membranes thus lies in their providing further evidence of the presence of a circulatory disturbance in such cases.

\section{Summary}

The presence of small thrombi in the hepatic sinusoids of the newborn is described, and their incidence is shown to be significantly higher in babies with pulmonary hyaline membranes. In the series of adult livers examined similar thrombi are found, with one exception, only where there is chronic venous congestion or focal necrosis, and it is suggested that in the newborn their increase indicates a disturbance of circulation.

My thanks are due to Professor A. C. P. Campbell for his advice on the preparation of this paper, to Professor W. I. C. Morris in whose department the work reported was performed, and to Dr. F. A. Langley for allowing me access to the autopsy material. Some of the observations are presented in a thesis accepted for the degree of Doctor of Medicine by the University of London.

\section{REFERENCES}

Benitez, R. E. (1952). Degenerative changes in liver associated with aspiration of vernix and hyaline membrane formation in lungs in intrauterine anoxia. A.M.A. Arch. Path., 54, 378.

Boyd, J. F. (1958). Two possible cases of acquired hypofibrinogenemia in the newborn. Surg. Gynec. Obstet., 106, 176.

Emery, J. L. (1952). Degenerative changes in the left lobe of the liver in the newborn. Arch. Dis. Childh., 27, 558.

(1953). Involution of the left liver in the newborn and its relationship to physiological icterus. Ibid., 28, 463.

(1956). The distribution of haemopoietic foci in the infantile human liver. J. Anat. (Camb.), 90, 293.

and Finch, E. (1954). The fat and water content of the left and right liver before and after birth. Arch. Dis. Childh., 29,242 .

Gruenwald, P. (1949). Degenerative changes in the right half of the liver resulting from intra-uterine anoxia. Amer. J. clin. the liver resulting.
Path., 19, 801 .

McFarlane, D. (1044). Picro-Mallory; an easily controlled regressive trichromic staining method. Stain. Technol., 19, 29.

Popper, H. and Schaffner, F. (1957). Liver; Structure and Function, p. 486. McGraw-Hill, New York. 